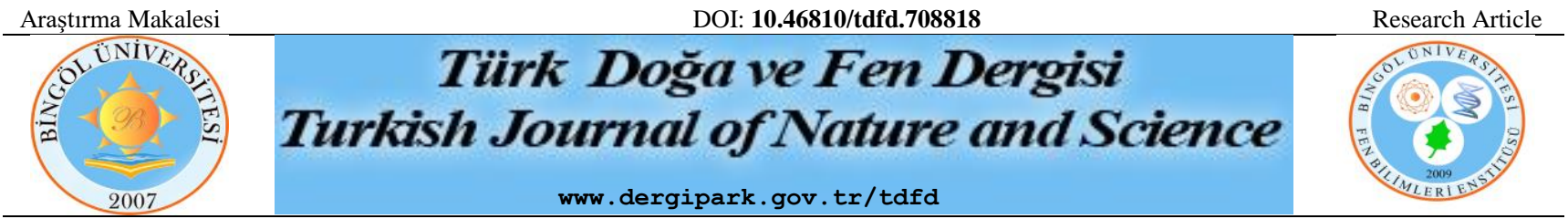

\title{
Tokat ve Yozgat Bölgelerinden Toplanan Bazı Yenilebilir Mantarların Antimikrobiyal Potansiyeli Üzerine Bir Araştırma
}

\author{
Hakan IŞIK ${ }^{1}$, İsa KARAMAN ${ }^{2}$, İbrahim TÜRKEKUL ${ }^{3^{*}}$ \\ ${ }^{1}$ Tokat M. Emin Saraç Anadolu İmam Hatip Lisesi, 60030, Tokat, Türkiye \\ ${ }^{2}$ Tokat Gaziosmanpaşa Üniversitesi, Mühendislik ve Doğa Bilimleri Fakültesi, Biyomühendislik Bölümü, 60240, Tokat, \\ Türkiye \\ ${ }^{3}$ Tokat Gaziosmanpaşa Üniversitesi, Fen-Edebiyat Fakültesi, Biyoloji Bölümü, 60240, Tokat, Türkiye \\ Hakan IŞIK ORCID No: 0000-0001-8241-0078 \\ İsa KARAMAN ORCID No: 0000-0001-5663-8941 \\ İbrahim TÜRKEKUL ORCID No: 0000-0002-1036-9835
}

*Sorumlu yazar: ibrahim.turkekul@gop.edu.tr

(Alınış: 24.03.2020, Kabul: 04.06.2020, Online Yayınlanma: 18.06.2020)

Anahtar
Kelimeler
Antimikrobiyal
aktivite,
Disk difüzyon
test,
Makrofungus,
Tokat,
Yozgat

Anahtar

Kelimeler aktivite,

Disk difüzyon

test,

Tokat,

Yozgat
Öz: Günümüzde mantarların kimyasal yapısını tespit etmeye yönelik yapılan çalışmalar, vitamin, mineral, protein, esansiyel amino asitler ve doymamış yağ asitleri bakımından değerli besinler olduğunu ortaya çıkarmıştır. Ayrıca üretmiş oldukları kimyasal maddeler birçok endüstriyel alanda kullanılmaktadır. Son yıllarda özellikle biyoteknoloji, tıp ve farmakoloji alanında yapılan çalışmalar giderek artmıştır. Bu çalışmada Tokat ve Yozgat yörelerinden toplanan Agaricus campestris L., Morchella esculenta (L.) Pers., Pleurotus ostreatus (Jacq.) P. Kumm., Tricholoma terreum (Schaeff.) P. Kumm. mantarlarının çeşitli ekstraktlarının antimikrobiyal aktivitesi disk difüzyon metodu ile test edilmiştir. Çalışma sonunda, mantarlardan elde edilen ekstraktların bazı Gram (+) ve Gram (-) bakteriler (Proteus vulgaris, Escherichia coli, Bacillus cereus, Pseudomonas aeruginosa, Bacillus subtilis, Staphylococcus aureus, Salmonella enteritidis, Streptococcus pyogenes) ve baz1 mikrofunguslar (Candida albicans, Candida utilis) üzerinde farklı derecelerde antimikrobiyal aktiviteye sahip oldukları tespit edilmiştir.

\section{A Study on Antimicrobial Potential of Some Wild Edible Mushrooms Collected from Tokat and Yozgat Regions}

Keywords Antimicrobial activity, Disc diffusion test, Macrofungi, Tokat, Yozgat

\begin{abstract}
Nowadays, studies made to determinate the chemical structure of mushrooms have revealed that they are valuable nutrients in terms of vitamins, minerals, proteins, essential amino acids and unsaturated fatty acids. In addition, the chemicals that they produce are used in many industrial fields. Especially studies made in the field of biotechnology, medicine and pharmacology have increased in recent years. In this study, antimicrobial activities of various extracts of Agaricus campestris L., Morchella esculenta (L.) Pers., Pleurotus ostreatus (Jacq.) P. Kumm., Tricholoma terreum (Schaeff.) P. Kumm. collected from Tokat and Yozgat provinces has been tested by disk diffusion method. At the end of the study, it was determined that the extracts obtained from the mushrooms had antimicrobial activity at different degrees on some Gram (+) and Gram (-) bacteria (Proteus vulgaris, Escherichia coli, Bacillus cereus, Pseudomonas aeruginosa, Bacillus subtilis, Staphylococcus aureus, Salmonella enteritidis, Streptococcus pyogenes) and some microfungi (Candida albicans, Candida utilis).
\end{abstract}

edilebilmiştir. Tespit edilen mantarların yaklaşık 10 bin

\section{GİRIş}

Mantarlar dünyada tür çeşitliliği en fazla olan canlılardan biridir. Dünya genelinde yayılış gösteren 1.5 milyon mantar türü olduğu tahmin edilmektedir. Ancak bunlardan çok az bir kısmı şimdiye kadar tespit türünü makromantarlar oluşturmaktadır. Bunlardan 5020'si yenir özellikte ve 1820' ise tıbbi özellik gösteren makromantarlardır $[1,2]$.

Mantarlar ve bitkiler uzun yıllardan beri dünya çapında geleneksel ilaçlar olarak terapötik amaçlar için 
kullanılmıştır. Günümüzde doğal-sentetik antibiyotikler patojen mikroorganizmaların sebep olduğu enfeksiyon hastalıklarda tedavi edici amaçlı tercih edilmektedir. Ancak mikroorganizmaların bu ilaçlara direnç kazanması halk sağlığı açısından büyük problemlere neden olmaktadır. Bu olay, bitki ve mantarların ürettiği doğal antimikrobiyal maddelerin elde edilmesi çalışmalarını hızlandırmıştır. Ormanlık ve çayırlık alanlarda doğal olarak yetişen veya kültürü yapılarak elde edilen mantarlar polisakkaritler, glikopeptitler, alkaloidler, terpenler, triterpenoidler, saponinler, fenolik bileşikler, lektinler, flavonoidler, şizofillan, lentinan, ßglukan gibi maddeler içermektedir [3]. Mantarların genellikle düşük molekül ağırlıklı ikincil metabolitler olarak isimlendirilen maddeler ürettiği bilinmektedir. Bunlar birincil metabolik yolların sonunda üretilen maddelerden sentezlenirler. Genellikle kendilerinin büyüme, gelişme ve üreme gibi fizyolojik olaylarında rol almayan ve hücre dişına salgılanan bu maddelerin antimikrobiyal aktivite özelliği vardır. Ayrıca sıcaklık, ultraviyole 1şınımı, nem, tuzluluk, $\mathrm{pH}$ ve su konsantrasyonu gibi çevresel stresler mantarların fizyolojisini ve metabolik yollarını önemli ölçüde etkileyebilmektedir. Mantarların ürettiği sekonder metabolitler ile ilgili çalışmalar 1928'de Alexander Fleming'in penisilini keşfetmesiyle artarak günümüze kadar gelmiştir. Son yıllarda bu maddeler ile ilgili birçok çalışma yapılmaktadır. $\mathrm{Bu}$ çalışmalardan bazılarını antimikrobiyal aktivite testleri oluşturmaktadır. Ülkemizde mantarların terapötik amaçlar için kullanımından daha çok beslenme amaçlı olarak tüketimi daha yaygındır. $\mathrm{Bu}$ yüzden yenen mantarların antimikrobiyal, antiviral, antikanser, antioksidant gibi biyolojik aktivitelerini tespit etmek önem kazanmış ve bununla ilgili çalışmalar giderek artmıştır [3,4].

$\mathrm{Bu}$ çalışmadaki amacımız Tokat ve Yozgat illerinde farklı lokalitelerden toplanan yenen makromantarlar olan $P$. ostreatus, T. terreum, A. campestris ve $M$. esculenta'nın bazı Gram (+) ve Gram (-) bakteriler ile bazı mikrofunguslar üzerine olan antimikrobiyal aktivitelerini tespit etmektir.

\section{MATERYAL VE METOT}

P. ostreatus, T. terreum, A. campestris ve M. esculenta olarak teşhis edilen mantar örnekleri 2014-2018 yılları arasında gerçekleşen arazi gezileri sırasında Tokat ve Yozgat illerinin farklı lokalitelerinden toplanmıştır. Mantar örneklerine ait bazı özellikler Tablo 1'de verilmiştir.

Arazi gezileri sırasında tespit edilen mantar örneklerinin Canon EOS 600D marka fotoğraf makinesi ile renkli fotoğrafları çekilmiş, morfolojik ve ekolojik özellikleri not edilmiştir. Laboratuvara getirilen örneklerden spor izi alınmış ve kurutulmuştur. Mantar örneklerinin mikroskopik özellikleri kuru örnekler kullanılarak elde edilmiştir. Bunun için bazı kimyasallar (distile su, $\mathrm{KOH} \% 5$, kongo kırmızısı, laktofenol gibi) ve Nikon marka araştırma mikroskopu kullanılmıştır. Morfolojik ve ekolojik özellikleri ortaya çıkarılan mantarlar mevcut literatür $[5,6,7,8,9,10,11]$ yardımıyla teşhis edilmiştir.
Antimikrobiyal aktivitesi test edilen makromantarın sistematiği Index Fungorum'a uygun olarak yazılmıştır [12]. Mantar ekstraklarının hazırlanması işleminde Soxhlet cihazı kullanılmıştır. Toz haline getirilen her bir mantar örneğinden 10 gr. alınmış ve sırasıyla aseton, etanol ve etil asetat çözücüleri kullanılarak cihazda ekstraksiyona tabii tutulmuştur. Elde edilen ekstraktlar, rotary evaporatör kullanılarak $40^{\circ} \mathrm{C}$ 'de konsantre edilmiş ve $+4^{\circ} \mathrm{C}^{\prime} \mathrm{de}$ saklanmıştır. Antimikrobiyal aktivite testinde disk difüzyon yöntemi uygulanmıştır [13].

\begin{tabular}{|c|c|c|}
\hline $\begin{array}{l}\text { Mantar } \\
\text { Türleri }\end{array}$ & Familya & Lokaliteler \\
\hline \multirow[t]{2}{*}{ A. campestris } & \multirow[t]{2}{*}{ Agaricaceae } & $\begin{array}{l}\text { Tokat-Akbelen yaylası, } \\
\text { çayırlık alan }\end{array}$ \\
\hline & & $\begin{array}{l}\text { Yozgat-Kadışehri, meşe } \\
\text { ormanı çayırlık alan }\end{array}$ \\
\hline \multirow[t]{2}{*}{ M. esculenta } & \multirow[t]{2}{*}{ Morchellaceae } & $\begin{array}{l}\text { Tokat-Yaylacık dağı- } \\
\text { Orman deposu, Pinus } \\
\text { sylvestris ormanı }\end{array}$ \\
\hline & & $\begin{array}{l}\text { Yozgat-Akdağmadeni, } \\
\text { Pinus sylvestris ormanı }\end{array}$ \\
\hline \multirow[t]{2}{*}{ P. ostreatus } & \multirow[t]{2}{*}{ Pleurotaceae } & $\begin{array}{l}\text { Tokat merkez- Akbelen } \\
\text { köyü, karışı orman }\end{array}$ \\
\hline & & $\begin{array}{l}\text { Yozgat-Kadışehri, meşe } \\
\text { ormanı }\end{array}$ \\
\hline \multirow[t]{2}{*}{ T. terreum } & \multirow[t]{2}{*}{ Tricholomataceae } & $\begin{array}{l}\text { Tokat merkez, } \\
\text { Pinus sylvestris ormanı }\end{array}$ \\
\hline & & $\begin{array}{l}\text { Yozgat-Akdağmadeni, } \\
\text { Pinus sylvestris ormanı }\end{array}$ \\
\hline
\end{tabular}

Mikrofunguslar ve bakteriler için besi yeri olarak Mueller Hinton Agar kullanılmıştır. Daha önce hazırlanan bakteri ve mikrofungus süspansiyonlarından $0.1 \mathrm{ml}$ alınarak besi yerine ekilmiş, ekstraktlardan $20 \mu \mathrm{l}$ emdirilmiş $6 \mathrm{~mm}$ çapındaki diskler belirli aralıklarla besi yerine yerleştirilmiştir. Bakteriler için Sulbactam/Cefoperazone (SCF $105 \mu \mathrm{g}) \quad$ ve mikrofunguslar için Nistatin $(100 \mu \mathrm{g})$ bulunduran diskler karşılaştırma amacıyla besi yerlerine yerleştirilmiştir. Bakteri aşılanan petriler $37^{\circ} \mathrm{C}$ 'de 24 saat, maya suşunun aşılandığı petriler ise $28^{\circ} \mathrm{C}$ 'de $3-4$ gün süre ile inkübe edilmiştir. Süre sonunda petri kaplarında disklerin çevresinde oluşan inhibisyon zonları $\mathrm{mm}$ olarak ölçülmüştür. Zon çapları çok küçük olan sonuçlar dikkate alınmamıştır. Çalışmalar 3 tekrar şeklinde yapılmıştır. Aseton, etanol ve etil asetat çözücüleri negatif kontrol olarak kullanılmıştır.

Çalışma sonucunda elde edilen veriler SPSS (versiyon 17.0) yazılımı ile analiz edilmiştir. Mantarlardan elde edilen ekstraktların ve antibiyotiğin oluşturduğu zon çapları tek yönlü varyans analizi (ANOVA) kullanılarak karşılaştırılmıştır.

\section{BULGULAR}

$\mathrm{Bu}$ çalışmada Tokat ve Yozgat illerinde yapılan arazi gezileri sırasında doğal ortamlarından toplanan yenilebilir $P$. ostreatus, $T$. terreum, A. campestris ve $M$. esculenta'nın antimikrobiyal ve antifungal aktiviteleri disk difüzyon metodu ile test edilmiştir. Boş antibiyotik disklere emdirilen mantar ekstrelerinin besi yerinde oluşturduğu zon çapları ve karşılaştırma için kullanılan antibiyotiğin oluşturduğu zon çapları Tablo 2'de 
gösterilmiştir. Çalışmanın sonucunda $P$. ostreatus, $T$. terreum, A. campestris ve $M$. esculenta makromantarlarının Tokat yöresinden toplanan örnekleri ile Yozgat yöresinden toplanan örneklerinden elde edilen ekstraktların farklı derecelerde antimikrobiyal aktiviteye sahip olduğu tespit edilmiştir.

$P$. ostreatus'un Tokat'tan toplanan örneklerinde oluşan zon çaplarının minimum $6.50 \pm 0.50 \mathrm{~mm}$, maksimum $14.00 \pm 1.00 \mathrm{~mm}$; Yozgat'tan toplanan örneklerinde ise minimum $9.00 \pm 0.00 \mathrm{~mm}$, maksimum $14.00 \pm 0.86 \mathrm{~mm}$ olduğu tespit edilmiştir. Yozgat yöresinden toplanan $P$. ostreatus'un etil asetat ekstraktlarının $B$. cereus ve $E$. coli üzerinde antimikrobiyal etkisinin olmadığı, Tokat yöresinden toplanan örneklerin ise düşük aktiviteye sahip olduğu görülmüştür. Hem Yozgat hem de Tokat'tan toplanan örneklerin aseton ekstraktlarının ise $P$. aeruginosa üzerinde antimikrobiyal etkilerinin olmadığ 1 gözlenmiştir. Tokat yöresinden toplanan $P$. ostreatus'un aseton ekstraktlarının $B$. subtilis, $S$. enteritidis, $S$. pyogenes, $C$. albicans ve $C$. utilis üzerinde, etanol ekstraktlarının ise $P$. vulgaris, $S$. Enteritidis ve $S$. pyogenes üzerinde güçlü antimikrobiyal aktivite gösterdiği tespit edilmiştir. Yozgat yöresinden toplanan $P$. ostreatus'un aseton ekstraktlarının B. subtilis, E. coli, $S$. enteritidis, $S$. pyogenes, $C$. albicans ve $C$. utilis üzerinde; etanol ekstraktlarının ise B. cereus, B. subtilis, $P$. vulgaris, $S$. enteritidis, $S$. aureus ve $C$. albicans üzerinde güçlü antimikrobiyal aktivite göstermiştir. Yozgat yöresinden toplanan $P$. ostreatus'un etil asetat ekstraktlarının, Tokat yöresinden toplanan örneklerden elde edilen etil asetat ekstraktlarına göre test mikroorganizmaları üzerinde daha fazla etkili olmuştur (Tablo 2).

Tokat'tan toplanan T. terreum örneklerinde minimum $6.50 \pm 0.86 \mathrm{~mm}$, maksimum $15.50 \pm 0.86 \mathrm{~mm}$; Yozgat'tan toplanan örneklerinde ise minimum $6.66 \pm 0.57 \mathrm{~mm}$, maksimum $16.00 \pm 1.00 \mathrm{~mm}$ zon çap1 tespit edilmiştir. Tokat yöresinden toplanan $T$. terreum'dan elde edilen aseton ve etanol ekstraktların $P$. vulgaris üzerinde, aseton ekstraktının ise $S$. aureus üzerinde etkili olmadığ görülmüştür. $P$. aeruginosa üzerinde etil asetat, $S$. pyogenes üzerinde ise etanol ekstraktları etkili olmamıştır. Makromantardan elde edilen ekstraktlar diğer mikroorganizmalar üzerinde farklı derecelerde etkili olmuştur. B. cereus üzerinde tüm ekstraktlar kuvvetli aktivite göstermiştir. Yozgat'tan toplanan $T$. terreum örneklerinden elde edilen etil asetat ekstraktı $P$. aeruginosa ve $S$. aureus üzerinde, etanol ekstraktı $S$. pyogenes üzerinde, aseton ekstraktı ise $S$. aureus üzerinde etkili olmamıştır. Diğer mikroorganizmalar üzerinde farklı zon çapları ile zayıf etkiden kuvvetli etkiye kadar değişik derecelerde antimikrobiyal aktivite göstermiştir. Mantarın tüm ekstraktları, Tokat örneklerinde olduğu gibi $B$. cereus üzerinde kuvvetli antimikrobiyal etki göstermiştir.

A. campestris'in Tokattan toplanan örneklerinde minimum $6.66 \pm 0.57 \mathrm{~mm}$, maksimum $13.66 \pm 0.57 \mathrm{~mm}$; Yozgat'tan toplanan örneklerinde ise minimum $7.00 \pm 0.00 \mathrm{~mm}$, maksimum $15.00 \pm 0.00 \mathrm{~mm}$ zon çap1 tespit edilmiştir. Tokat yöresinden toplanan $A$. campestris örneklerinden elde edilen aseton ekstraktlarının $E$. coli, $P$. vulgaris, $P$. aeruginosa üzerinde yeterli zon çapı oluşturamadığ $; B$. cereus ve $S$. aureus üzerinde ise düşük aktivite gösterdiği tespit edilmiştir. Yine bu mantar örneklerinin etil asetat ekstraktlarının B. cereus, $P$. aeruginosa, $S$. enteritidis, $C$. albicans ve $C$. utilis üzerinde etkili olmadığı görülmüştür. $\mathrm{Bu}$ ekstraktlar diğer mikroorganizmalar üzerinde değişik zon çapları oluşturabilmiştir. Etanol ekstraktlarının tüm bakteriler üzerinde farklı derecelerde antimikrobiyal aktivite gösterdiği görülmüştür. $A$. campestris'in Yozgat'tan toplanan örneklerinin aseton ekstraktlarının E. coli, $P$. vulgaris, $P$. aeruginosa, $S$. aureus üzerinde; etil asetat ekstraktlarının $B$. cereus, $B$. subtilis, $P$. aeruginosa, S. enteritidis, S. pyogenes, $C$. albicans ve $C$. utilis üzerinde etkili olmadığ görülmüştür.

M. esculenta'nın Tokattan toplanan örneklerinde minimum $8.33 \pm 0.57 \mathrm{~mm}$, maksimum $15.83 \pm 1.25 \mathrm{~mm}$; Yozgat'tan toplanan örneklerinde ise minimum $6.66 \pm 0.57 \mathrm{~mm}$, maksimum $16.16 \pm 1.04 \mathrm{~mm}$ zon çap1 tespit edilmiştir. $M$. esculenta'nın Tokat yöresinden toplanan örneklerinde aseton ve etanol ekstraktları tüm mikroorganizmalar üzerinde etkili olmuştur. Ancak etil asetat ekstraktı $S$. pyogenes, $C$. albicans ve $C$. utilis üzerinde etki göstermemiştir. Diğer mikroorganizmalar üzerinde farklı büyüklükte zon çap1 oluşturarak etkili olmuştur. $\mathrm{Bu}$ makromantarın Yozgat'tan toplanan örneklerin etil asetat ekstraktı $S$. pyogenes üzerinde zayıfta olsa antimikrobiyal etki gösterirken, Tokat'tan toplanan örnekler yeterli büyüklükte zon çap1 oluşturamamıştır (Tablo 2).

\section{SONUÇ}

Mevcut çalışmada doğal ortamlarından toplanan yenen dört farklı makromantar türünün antimikrobiyal aktiviteleri, on patojenik organizmaya karşı disk difüzyon yöntemi ile belirlenmiştir. Tablo 2'de farklı çözücüler (aseton, etanol ve etil asetat) kullanarak elde edilen mantar ekstraktlarının zon çapları verilmiştir.

Vamanu ve ark. [14] çalışmalarında Pleurotus ostreatus'un kültür formundan elde edilen etanol ekstraktlarının E.coli, B. cereus ve Listeria innocua üzerinde 10-20 mm arasında değișen zon çap1 ile antimikrobiyal aktiviteye sahip olduğunu tespit etmişlerdir. Bizim çalışmamızda doğal ortamdan toplanan Pleurotus ostreatus'un etanol ekstraktları E.coli ve $B$. cereus üzerinde $9.00 \pm 1.00-11.50 \pm 0.86$ arasinda değişen zon çapı oluşturarak etkili olmuştur.

Singha ve ark. [15] tarafindan yapılan çalıșmada Pleurotus ostreatus'un aseton ekstraktının Staphylococcus aureus ve Klebsiella pneumonia patojenlerine karşı dikkate değer antibakteriyel etkisinin olduğu belirlenmiştir. Bizim çalışmamızda ise bu mantardan elde edilen aseton ekstraktları S. aureus patojenine karş1 $10.33 \pm 0.28$ ve $11.00 \pm 0.00 \mathrm{~mm}$ zon çapları oluşturmuştur. 


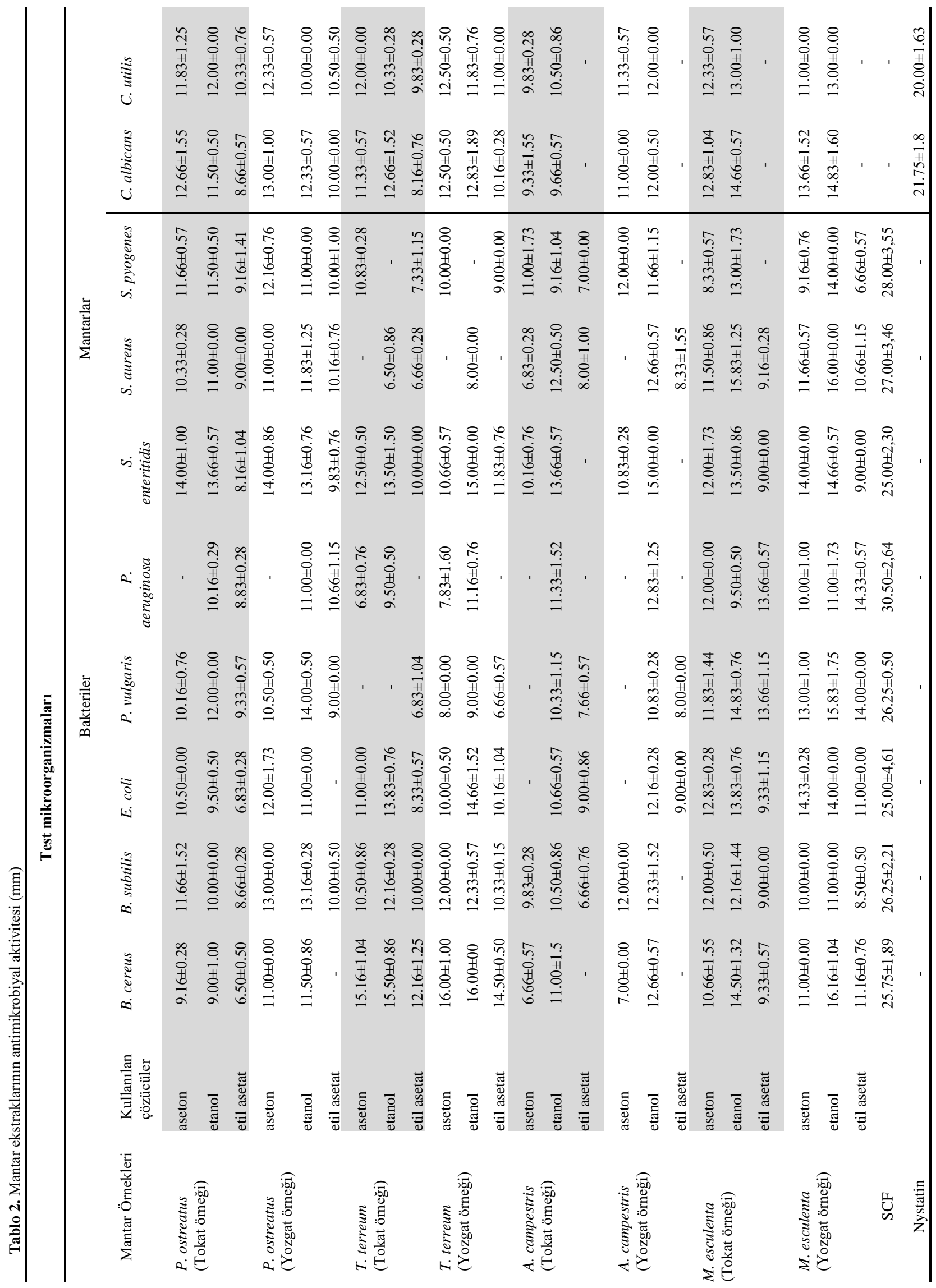

Kalyoncu ve ark. [16]'nın yaptığı çalışmada Pleurotus ostreatus'un laboratuvar ortamında yetiştirilen misellerinden hazırlanan etanol ekstraktları $S$. aureus, $E$. coli, B. cereus, C. albicans, B. subtilis, P. vulgaris üzerine sırasıyla $24,18,16,12,12,8 \mathrm{~mm}$ zon çap1 oluşturarak etkili olmuştur. Bizim çalışmamızda aynı patojenlere karşı etanol ekstraktları S. aureus, E. coli ve $B$. cereus üzerinde daha düşük zon çapı oluştururken $C$. 
albicans, B. subtilis ve $P$. vulgaris üzerinde daha büyük zon çap1 oluşturmuştur (Tablo 2).

Agaricus campestris' in antimikrobiyal aktivitesini tespit etmeye yönelik Giri ve ark. [17] tarafindan yapılan çalışmada, metanol ekstraktlarının Staphylococcus aureus, Bacillus cereus, Escherichia coli üzerinde etkili olmadığı, Bacillus subtilis, Proteus vulgaris, Pseudomonas aeruginosa, Candida albicans üzerinde ise antimikrobiyal aktivitesi olduğu tespit edilmiştir.

Bizim yaptığımızda çalışmada A. campestris'in hem Tokat hem de Yozgat'tan toplanan örneklerinden elde edilen ekstraktların Staphylococcus aureus, Bacillus cereus ve Escherichia coli üzerinde farklı derecelerde zon çapı oluşturarak etkili olduğu görülmüştür. Aynı çalışmada Pleurotus ostreatus'dan elde edilen metanol ekstraktların Bacillus cereus ve Candida albicans üzerinde etkili olmadığ1, Bacillus subtilis, Proteus vulgaris, Pseudomonas aeruginosa, Staphylococcus aureus ve Escherichia coli üzerinde ise aktivite gösterdiği belirlenmiştir. Çalışmamızda Pleurotus ostreatus'dan elde edilen farklı ekstraktların Bacillus cereus üzerine $6.50 \pm 0.50-11.50 \pm 0.86$ arasında zon çap1 ile, Candida albicans üzerine ise $8.66 \pm 0.57-13.00 \pm 1.00$ arasında zon çap1 oluşturarak etkili olduğu görülmüştür. $\mathrm{Bu}$ iki çalışmada elde edilen sonuçların farklı olması kullanılan çözücülerin farklılığından kaynaklanmış olabilir.

Jagadish ve ark. [18], A. campestris makromantarına yakın bir tür olan Agaricus bisporus üzerinde antimikrobiyal aktivite çalışmaları yapmıştır. Sonuçta etanol ekstraklarının test için kullandıkları Gram (-) bakteriler üzerine zayıf etkilerinin olduğu, ancak Gram $(+)$ bakteriler üzerinde kuvvetli etkilerinin olduğunu tespit etmişlerdir. Makromantarın çiğ örneklerinin $S$. aureus, $B$. subtilis ve $P$. aeruginosa üzerinde sirasiyla $22 \pm 4, \quad 12 \pm 1, \quad 16 \pm 0.2 \mathrm{~mm}$ zon çap1 oluşturarak antimikrobial aktiviteye sahip olduğu belirlenirken, $E$. coli üzerinde yeterli zon çapı oluşturamamıştır. Ayrıca C. albicans üzerinde $14 \pm 0.5 \mathrm{~mm}$ zon çap1 oluşturarak antifungal etkiye sahip olduğu tespit edilmiştir. Çalışmamızda A. campestris örneklerinin etanol ekstraktları $S$. aureus üzerine $12.50 \pm 0.50$ ve $12.66 \pm 0.57$ $\mathrm{mm}$, B. subtilis üzerine $10.50 \pm 0.86$ ve $12.33 \pm 1.52 \mathrm{~mm}$, $P$. aeruginosa üzerine $11.33 \pm 1.52$ ve $12.83 \pm 1.25 \mathrm{~mm}$ ve E. coli üzerine $10.66 \pm 0.57$ ve $12.16 \pm 0.28 \mathrm{~mm}$ zon çap1 oluşturmuştur. C. albicans üzerinde $9.66 \pm 0.57$ ve $12.00 \pm 0.50 \mathrm{~mm}$ zon çapları oluşturarak Jagadish ve ark. [18]'nın sonuçlarına göre biraz daha düşük antifungal aktivite göstermiştir.

Yıldız ve ark. [19] tarafindan yapılan çalışmada Agaricus bisporus ve Pleurotus ostreatus'un kültür ortamında yetiştirilmiş örneklerinin metanol ekstraktlarının bazı bakteri (Escherichia coli, Staphylococcus aureus, Enterococcus faecalis, Klebsiella pneumoniae, Salmonella typhimurium, Acinetobacter haemolyticus, Proteus mirabilis, Pseudomonas aeruginosa) ve mayalara (Candida albicans) karşı antimikrobiyal aktiviteleri test edilmiştir. Analizler sonucunda, bu mantar ekstraktlarının test mikroorganizmalara karşı antimikrobiyal aktivitelerinin olmadığ 1 belirlenmiştir. Bizim analizlerimizde Pleurotus ostreatus örneklerinden elde edilen ekstraktların E. coli, S. aureus, $P$. aeruginosa ve $C$. albicans patojenlerine karş1 6.83 $\pm 0.28-13.00 \pm 1.00$ arasında değişen zon çapları ile antimikrobiyal aktiviteye sahip olduğu görülmüştür.

Canlı ve ark. [20] tarafindan Morchella esculenta'nın antimikrobiyal aktivitesini tespit etmek amaciyla yapılan çalışmada etanol ekstraktlarının B. subtilis, C. albicans, E. coli, $P$. aeruginosa, $S$. enteritidis, $S$. aureus ve $P$. vulgaris üzerine 7.00-13.00 $\mathrm{mm}$ arasında zon çap1 oluşturarak etkili olduğunu belirlemişlerdir. Çalışmamızda etanol ekstraktlarının $9.50 \pm 0.50$ $16.16 \pm 1.04 \mathrm{~mm}$ arasında zon çap1 oluşturduğu görülmüştür.

M. esculenta'nın 6 farklı patojene karşı antimikrobiyal aktivitesini belirlemek için yapılan bir çalışmada etil asetat ekstraktlarının E. coli, B. subtilis, S. pyogenes ve C. albicans üzerine etkili olmadığı, $P$. aeruginosa üzerinde $8 \mathrm{~mm}$ ve $S$. aureus üzerinde $10 \mathrm{~mm}$ zon çap1 oluşturarak etki gösterdiği belirlenmiştir [21]. Bizim örneklerimizden elde ettiğimiz etil asetat ekstraktları $E$. coli, B. subtilis, S. pyogenes, $P$. aeruginosa ve S. aureus üzerinde $6.66 \pm 0.57-14.33 \pm 0.57$ arasında değişen zon çapları oluşturarak antimikrobiyal aktivite gösterirken, C. albicans üzerinde yeterli zon çapı oluşturamamıştır.

Sadi ve ark. [22] tarafindan Tricholoma terreum üzerine yaptıkları çalışmada metanol ve su ekstraktları E. coli, $B$. subtilis ve $S$. aureus bakterilerine karşı $6-8 \mathrm{~mm}$ arasında değişen zon çap1 oluşturarak antibakteriyel etki gösterdiği görülmüştür. Çalışmamızda $T$. terreum'dan elde ettiğimiz aseton, etanol ve etil asetat ekstraktları aynı patojenlere karşı $6.66 \pm 0.28-14.66 \pm 1.52$ arasında değişen zon çapları oluşturmuştur.

Yapılan bu çalışmada Tokat ve Yozgat yöresinde yapılan arazi gezileri sırasında toplanan $P$. ostreatus, $T$. terreum, A. campestris ve $M$. esculenta'nın aseton, etanol ve etil asetat ekstraktlarının antimikrobiyal aktiviteleri test edilmiştir. Çalışma sonucunda Tokat'tan toplanan örnekler ile Yozgat'tan toplanan örnekler arasinda farklı zon çapları oluşmuştur. Yogabaanu ve ark. [4] göre su ve mineral miktarı, sicaklık, pH ve tuzluluk gibi çevresel faktörler antimikrobiyal aktivite gösteren sekonder metabolitlerin üretimi üzerinde etkili olabilmektedir.

\section{Teşekkür}

Antimikrobial aktivite testlerimizde yardımlarını esirgemeyen Tokat Gaziosmanpaşa Üniversitesi Fen Edebiyat Fakültesi Biyoloji Bölümü Mikrobiyoloji Laboratuvarı ve Mühendislik ve Doğa Bilimleri Fakültesi Biyomühendislik Bölümü Mikrobiyoloji Laboratuvarı uzman personeline teşekkür ederiz. Ayrıca Tokat Gaziosmanpaşa Üniversitesi Bilimsel Araştırma Projeleri Koordinasyon Birimine (GOU-BAP: 2012/048) bu çalışmayı finansal olarak desteklediği için teşekkür ederiz. Bu çalışmanın bir bölümü 1. Avrasya Mikoloji 
Kongresi'nde (3-5 Temmuz 2017, Manisa) poster sunumu yapılmıştır.

\section{KAYNAKLAR}

[1] Hawksworth DL. The magnitude of fungal diversity: the 1.5 million species estimate revisited. Mycological Research, 2001; 105(12): 1422-1432.

[2] Pekşen A. Mantarların İnsan Hayatı ve Sağlığındaki Yeri. Bahçe Haber, 2013; 2(1): 10-15.

[3] Akyüz M, Onganer AN, Erecevit P, Kırbağ S. Antimicrobial Activity of some Edible Mushrooms in the Eastern and Southeast Anatolia Region of Turkey. GUJS. 2010; 23(2): 125-130.

[4] Yogabaanu U., Weber JFF, Convey P., RizmanIdid M., Alias SA. Antimicrobial properties and the influence of temperature on secondary metabolite production in cold environment soil fungi. Polar Science, 2017; 14: 60-67.

[5] Phillips R. Mushrooms and Other Fungi of Great Britain \& Europe. Pan Books Ltd., 288 page, London; 1981.

[6] Moser M. Keys to Agarics and Boleti. Gustav Fischer Verlag, 535 page, Stuttgart; 1983.

[7] Bon M. The Mushrooms and Toadstools of Britain and North-Western Europe. Hodder-Stoughton, 352 page, London; 1987.

[8] Breitenbach J, Kränzlin F. Fungi of Switzerland. Vol: 3, Boletes and Agarics 1. Part, Verlag Mykologia CH-6000 Luzern 9, 361 page, Switzerland; 1991.

[9] Breitenbach J, Kränzlin F. Fungi of Switzerland. Vol: 4, Agarics 2. Part, Verlag Mykologia $\mathrm{CH}-$ 6000 Luzern 9, Switzerland; 1995.

[10] Jordan M. The Encyclopedia of Fungi of Britain and Europe. Frances Lincoln, London; 1995.

[11] Beug MW, Bessette AE, Bessette AR. Ascomycete Fungi of North America. Austin, TX, University of Texas Press, USA; 2014.

[12] Kirk P. [Internet]. Index Fungorum; 2011 (erişim tarihi: 20 Aralı 2019 ). URL: http://www.indexfungorum.org

[13] Murray PR, Baron EJ, Pfaller MA, Tenover FC, Yolke RH. Manual of Clinical Microbiology. 7th edition, American Society Microbiology; 2003.

[14] Vamanu E, Ene M, Vamanu A, Smarandache D, Sârbu I, Popa O, et al. Antioxidant and antibacterial properties of the extracts from Pleurotus ostreatus EVFB1 and EVFB4. Romanian Biotechnological Letters, 2011; 16: 40-46.

[15] Singha K, Pati BR, Mondal KC, Mohapatra PKD. Study of nutritional and antibacterial potential of some wild edible mushrooms from Gurguripal Ecoforest, West Bengal, India. IJBT. 2017; 16: 222-227.

[16] Kalyoncu F, Oskay M, Sağlam H, Erdoğan TF, Tamer AÜ. Antimicrobial and Antioxidant Activities of Mycelia of 10 Wild Mushroom Species. Journal of Medicinal Food, 2010; 13(2): 415-419.

[17] Giri S, Biswas G, Pradhan P, Mandal SC, Acharya K. Antimicrobial Activities of Basidiocarps of Wild
Edible Mushrooms Of West Bengal, India. Int. J. PharmTech Res. 2012; 4(4): 1554-1560.

[18] Jagadish LK, Krishnan VV, Shenbhagaraman R, Kaviyarasan V. Comparitive study on the antioxidant, anticancer and antimicrobial property of Agaricus bisporus (J. E. Lange) Imbach before and after boiling. Afr. J. Biotechnol. 2009; 8(4): 654-661.

[19] Yıldız S, Yılmaz A, Can Z, Tabbouche SA, Kılıç AO, Sesli E. Some Bioactive Properties of Wild and Commercial Mushroom Species. J Food Health Sci. 2017; 3(4): 161-169.

[20] Canlı K, Benek A, Şenturan M, Akata I, Altuner EM. In vitro Antimicrobial Activity of Morchella esculenta and Trametes versicolor. Mantar Dergisi, 2019; 10(özel say1): 28-33.

[21] Acay H. Yenilebilen Yabani Mantar Morchella esculenta (L.) Pers.'nın Besinsel Kalitesi ve Biyoaktif Özelliklerinin Değerlendirilmesi. Mantar Dergisi, 2018; 9(2): 95-105.

[22] Sadi G, Kaya A, Yalçın HA, Emsen B, Kocabaş A, Kartal DI, et al. Wild Edible Mushrooms from Turkey as Possible Anticancer Agents on HepG2 Cells Together with Their Antioxidant and Antimicrobial Properties. International Journal of Medicinal Mushrooms, 2016; 18(1): 83-95. 